\title{
EL TRIBUNAL DE LA CONCIENCIA Y \\ LA CONCIENCIA DEL TRIBUNAL (UNA REFLEXIÓN ÉTICO-JURÍDICA SOBRE LA LEY Y LA CONCIENCIA)
}

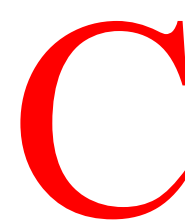

omo a cualquiera se le alcanza, el título de este trabajo responde a una bien conocida figura retórica -a la que cabría dar, entre otros, los nombres de «quiasmo»y de «retruécano»-, figura consistente en la inversión de los términos de dos frases consecutivas. Pero, lejos de interpretar tal título como un simple recurso y hasta un truco retórico, rogaría encarecidamente a los lectores que se lo tomen muy en serio, pues estoy convencido de que la idea que en él se expresa apunta al meollo de la cuestión de la ley y la conciencia sobre la que me propongo reflexionar en lo que sigue. Y de ahí que añada mis excusas por dedicar, como voy a hacer, una considerable parte del texto -si es que no incluso su totalidad- a explicitar la idea que dicho título insinúa, de suerte que aquéllos, si persisten en su lectura hasta el final, siempre podrán decir lo que el lector de ciertos libros pesados: " Afortunadamente, no conseguí pasar del título».

Comenzaremos, pues, por la metáfora del «tribunal de la conciencia». Aunque las alusiones a una supuesta «voz de la conciencia» se remontan a los orígenes de la literatura filosófica -como en el caso de la famosa «voz demónica», la phoné daitnoniké, que Sócrates oía en su interior y le avisaba contra la acción que estaba a punto de emprender, según éste nos cuenta, por boca de Platón, en su Apología-, el mejor ejemplo que en esa literatura se conoce de una concepción de la conciencia, y en particular de la conciencia moral, como un juez o un tribunal de nuestros actos lo encontramos en la filosofía moderna y, muy concretamente, en la obra de Kant, quien en su Metafísica de las costumbres, invocando el «tribunal interno al hombre» de San Pablo «ante el que sus pensamientos se acusan o se disculpan entre sí», escribiría que «la conciencia (Bewusstsein) de semejante tribunal interno al hombre es la conciencia moral 
(Gewissen)» ${ }^{1}$. En la lengua española, a diferencia de la alemana, no contamos con dos palabras distintas para designar respectivamente a la simple conciencia o consciencia a secas y a la conciencia moral, pero todos tenemos claro que ser consciente de que uno ha hecho algo no es exactamente lo mismo que serlo de que ese algo está mal o de que no debería haber sido hecho, y eso es todo cuanto se necesita a los efectos de preservar la distinción kantiana entre «conciencia» y «conciencia moral».

En cuanto a Kant, tras definir de aquella guisa la conciencia moral, procede a describirla en los siguientes términos un tanto escalofriantes: «Todo hombre tiene conciencia moral y se siente observado, amenazado y sometido a respeto -respeto unido al temor- por un juez interior; y esa autoridad que vela en él por las leyes no es algo producido arbitrariamente por él mismo, sino inherente a su ser. Cuando pretende huir de ella, le sigue como su sombra. Puede, sin duda, aturdirse y adormecerse con placeres y distracciones, mas no puede evitar volver en sí y despertar de cuando en cuando tan pronto como percibe su terrible voz. Puede incluso, en su extrema depravación, llegar a no prestarle atención, pero lo que no puede en ningún caso es dejar de oírla» ${ }^{2}$.

Para algunos, este texto de Kant sería una muestra más del sombrío pesimismo que se suele asociar a su así llamado rigorismo moral, pero tampoco faltará quien crea apreciar en él el cándido optimismo del ilustrado, del ilustrado cristiano por más señas, que mal que bien se las apaña para exaltar la condición eminentemente moral del ser humano. Después de todo, no deja de resultar dudoso que la voz de una conciencia moralmente ineducada consiga no ya hacerse oír, sino ni tan siquiera romper a hablar, de la misma manera que, sin la educación moral que habitúa al hombre a prestarle oídos, parece harto improbable que éste llegue a escuchar jamás la voz de su conciencia. Y todo ello por no hablar de la compleja estratificación e interarticulación de los diversos registros de esa voz con los que estamos bien familiarizados desde Freud. Lo que describe Kant como un rasgo de la naturaleza humana quizás no pase, pues, de reducirse a una contingencia psico-socio-histórica de la constitución del hombre como un sujeto moral. Y, aun así, la mudez y la sordera de, y ante, la voz de la conciencia tendrán todo el derecho a figurar entre los apartados o capítulos de una fenomenología moral medianamente digna de ese nombre.

Pero, por más que la voz de la conciencia permanezca frecuentemente

\footnotetext{
${ }^{1}$ Immmanuel Kant, Metaphysik der Sitten, Kants Werke, Akademic Ausgabe, vol. VI, pág. 438 (hay traducción castellana de A. Cortina y J. Conill, Madrid, 1989).

${ }^{2}$ Ibíd., loc. cit.
} 
sumida en la afonía y nosotros hagamos con no menos frecuencia oídos sordos a su llamado, esto es, por más exagerada que nos parezca la afirmación de Kant según la cual «todo hombre» tiene, y tiene siempre, conciencia moral, lo cierto es que a veces aducimos obligaciones de conciencia como motivos de nuestras acciones y experimentamos sentimientos de culpa o remordimientos de conciencia cuando obramos en contra de sus dictados. Negar estos fenómenos también sería atentar contra la fenomenología moral y, desde luego, haría ininteligible la lectura no sólo ya del Nuevo Testamento, sino la de un sinnúmero de piezas de la historia literaria -desde Esquilo a Dostoyevski-, así como la obra de unos cuantos filósofos morales, Kant sin duda entre ellos. De modo que admitido, con todas la cautelas que se quieran, que existe algo así como la conciencia moral, la cuestión pasa a ser cómo habríamos de entender para nuestros efectos la caracterización kantiana de la misma que acabamos de ver, esto es, su caracterización como un «tribunal» que nos obliga a desdoblarnos a la vez en jueces y acusados.

Por lo que se refiere a tal desdoblamiento, se trata de un ejemplo, entre otros posibles, de lo que modernamente se conoce como la estructura reflexiva de nuestra subjetividad. La filosofía moderna, como tantas veces se ha dicho, no sólo ha sido hasta ayer mismo una «filosofía de la conciencia», sino una filosofía de la «autoconciencia», autoconciencia presupuesta en el célebre cogito cartesiano, puesto que nadie puede decir «Pienso» sino gracias a esa reflexividad que le permite cobrar conciencia de sí mismo en tanto que sujeto pensante o cognoscente. $\mathrm{Y}$ otro tanto vendría a acontecer con nuestra condición de sujetos agentes más bien que cognoscentes $\mathrm{y}$, en especial, con nuestra condición de sujetos morales. Lo que Kant llama «juicio» desde un punto de vista moral (iudicium) descansa en la capacidad que tiene ese sujeto de desdoblarse en sí mismo y en otro, un otro al que el sujeto pone por juez de sus propios actos y ante el que se presenta como si lo hiciera «ante una audiencia» (coram iudicio), mas con la particularidad de que la ley, la ley moral, con que aquel otro ha de juzgarle no es -advierte Kant- sino la ley que el sujeto «se ha dado a sí mismo» ${ }^{3}$. Pues en el tribunal de la conciencia, el sujeto moral no sólo es, además de «reo», «juez», sino también «legislador» o autolegislador. Con otras palabras, lo característico del sujeto moral no es ya, o no es sólo, el atributo de la autoconciencia, sino el más decisivo de la autonomía. Naturalmente, el sujeto moral no siempre se halla en situación de «inventarse» los contenidos

${ }^{3}$ Kant. op. cit, págs. 379 y ss.. 388-9,437 y ss.: cfr. asimismo Grundelegung zur Metaphysik der Sitten, K. W., Ak., vol. IV, págs. 432 y ss., 446-9 (hay trad. cast. de M. García Morente, Madrid, 1921, y L. Martínez de Velasco, Madrid, 1990). 
de su moral, como a veces han hecho los grandes moralistas o reformadores morales a lo largo de la historia, sino que dichos contenidos proceden normalmente de estos o aquellos «códigos morales» vigentes en su tiempo y en su sociedad, siendo las «fuentes» de tal moralidad las religiones, las concepciones del mundo y de la vida, las ideologías políticas, etcétera. Pero aunque tales contenidos morales son, en un obvio sentido, «heterónomos», esto es, advienen a la conciencia moral desde una instancia ajena a ella, el sujeto moral siempre podrá asumirlos «autónomamente» si ésa es su voluntad, con lo que el nómos en cuestión dejaría de ser heterónomo para pasar a convertirse en ley moral autónoma: como Kant diría en otra parte, la existencia de semejante ley moral autónoma nos lleva a conocer que somos «libres»o, si lo preferimos decir así, la libertad se convierte ni más ni menos que en la razón de ser de la ley moral y de nuestra mismísima condición de sujetos morales ${ }^{4}$. $\mathrm{Y}$ es que, en efecto, la libertad no sólo hace posible que nos demos a nosotros mismos «nuestra propia ley», sino también hace posible que seamos «capaces de cumplirla o incumplirla». Es decir, nos transforma en responsables de nuestros actos y permite, en fin, que dichos actos lleguen a sernos imputados (in meritum aut demeritum, escribe Kant) y seamos por ellos condenados o absueltos cuando el tribunal de la conciencia, concluido el proceso que hemos estado describiendo, pronuncie su sentencia.

Pero con esto de la libertad hemos tocado una cuestión crucial para la ética y, por lo pronto, para la ética de Kant que nos servía de punto de partida. Me refiero al problema que Kant se planteó bajo la forma de una famosísima antinomia, la tercera antinomia de la Crítica de la razón pura, la «antinomia de la causalidad y la libertad» ${ }^{5}$ : al igual que los restantes acontecimientos de este mundo, las acciones humanas tendrían que poder ser explicadas causalmente; pero, a diferencia del resto de los seres de este mundo, los hombres acostumbran a concebirse a sí mismos como libres, según nosotros mismos acabamos de comprobar (quien haga suya la tesis de la libertad, tendría que renunciar a la posibilidad de suministrar una explicación causal de sus propias acciones; mientras que, para quien se instale en la antítesis de la causalidad, tal libertad no pasaría de imaginaria, no habría en rigor lugar a hablar de ella, la tesis de la libertad se vendría abajo). En nuestros días, no han faltado filósofos -como es, señaladamente, el caso de Karl Popper- que retomen el planteamiento kantiano convencidos de que la antinomia se torna

${ }^{4}$ I. Kant, Kritik der praktischen Vernunft, Ak., vol. V, pág. 4 (hay trad. cast. de M. García Morente, Madrid, 1913).

${ }^{5}$ I. Kant, Kritik der reinen Vernunft, Ak., vol. IV, A 444-51, B 472-9 (hay trad. cast. de P. Ribas, Madrid. 1978). 
resoluble con sólo cambiar el concepto de ciencia envuelto en ella. En su caso, sustituyendo el determinismo universal de la ciencia newtoniana, a la que Kant nunca dejó de serle fiel, por una concepción indeterminista la ciencia como la que Popper siempre ha gustado de hacer suya. Por un lado, nos dirá, ni tan siquiera máquinas tan perfectamente determinadas como lo son en apariencia los relojes se salvarían de verse afectadas por factores fortuitos, como los derivados de la fricción. Por otro lado, fenómenos tan aparentemente indeterminados como las nubes estarían a su vez lejos de exhibir una perfecta aleatoriedad, como lo prueba el hecho de que seamos capaces de predecir el tiempo. En cuanto a los hombres y sus acciones, vendrían a ocupar -para decirlo con el título de un conocido trabajo de Popper- un lugar intermedio entre las nubes y los relojes. Además del mundo físico en que se ubican sus cuerpos y del mundo mental constituido por sus conciencias, los seres humanos interaccionan por ensayo y error en, y con, un tercer mundo que es el universo poblado por sus productos simbólicos, incluidos entre ellos sus teorías científicas y también sus instituciones sociales: unas y otras influyen sobre el medio en que se desenvuelve la conducta humana, desde donde reobran sobre ésta gracias a una suerte de efecto de retroalimentación (en consecuencia, una cierta «determinación de la conducta» por el medio resulta inevitable, pero tal determinación nunca es completa, resultando a su vez el medio susceptible de ser «determinado por el hombre»; que es lo que Popper trata de expresar recurriendo a la idea de un control plástico de la conducta por el medio y viceversa ${ }^{6}$, idea que según él nos daría pie a escapar del determinismo y salvaguardar la libertad). Por lo que a mí respecta, sin embargo, dudo mucho que la de Popper constituya ninguna superación de la antinomia kantiana y creo más bien que el problema que Kant se planteaba permanece absolutamente intacto.

La distinción de este último entre causalidad y libertad se doblaba, en rigor, de otras dos distinciones muy importantes para Kant. En primer lugar, una distinción de carácter epistémico-metafísico, a saber, la distinción entre el mundo sensible -que Kant llamaba fenoménico-, presidido por una trama de relaciones de causa-efecto, y un mundo allende dicho mundo empírico, un mundo inteligible llamado por Kant nouménico y en el que emplazaría al sujeto libre. Se trata, como vemos, de una distinción de notable densidad metafísica, a la que tendríamos que rebajar de grado para adaptarla a estos tiempos que no en vano se califican de «postmetafísicos». Y, junto a ella, tendríamos otra distinción -esta vez de carácter metafísico-moral-, a

${ }^{6}$ K. R. Popper, Objective Knowledge, Londres, 1972. págs. 206 y ss. (hay trad. cast. de C. Solís, Madrid. 1982). 
saber, la distinción entre el mundo del ser y el del deber-ser, distinción que, por más metafísica que nos parezca, quizás podamos formular en términos ametafísicos, pero tenemos en cualquier caso que asumirla si deseamos distinguir no ya entre dos tipos de ciencia como Popper, sino entre ciencia y ética. Considerémoslas por este orden.

La primera de dichas distinciones tendría que ser hoy rechazada si con ella nos obligásemos a aceptar que el sujeto libre sea un «sujeto nouménico», sustraído por tanto al orden de la causalidad, ni mucho menos algo por el estilo de lo que la tradición filosófica prekantiana llamaba un «yo substancial», un yo que se hallase por debajo del, o sotopuesto al, yo empírico de cada cual (lo que los griegos denominaron hypokeímenon -traducido por los latinos por subjectum-, así como hypóstasis, traducido por los latinos por persona $)^{7}$. No hay evidentemente nada de eso. El sujeto moral, en tanto que sujeto libre, no se halla sotopuesto ni superpuesto al -ni por debajo ni por encima del- sujeto de carne y hueso que somos cada uno, que además tampoco somos substancias en el sentido de algo hecho y derecho desde el comienzo hasta el final de nuestra vida, sino seres en devenir, perpetuamente in fieri desde que nacemos hasta que morimos, el único momento en que podría decirse que hemos terminado de hacernos y que justamente coincide con el momento en que dejamos de serlo todo, hasta de ser sujetos, por lo menos si no creemos en la inmortalidad personal. Pero quizás quepa expresar algo bastante semejante a lo que Kant quería decir en términos más sobrios y lingüísticos. Como Habermas ha insistido en recordar recientemente, pero apuntaron antes que él los filósofos analíticos, la filosofía se halla instalada hoy bajo el signo del pensamiento postmetafísico gracias a lo que se ha dado en llamar el «giro lingüístico» del pensamiento contemporáneo, esto es, aquel que nos invita a reemplazar la vieja filosofía de la conciencia por una «filosofía del lenguaje», capaz de expresar valiéndose de categorías lingüísticas -relativamente aprensibles y manejables- las inaprensibles y a veces inmanejables categorías metafísicas de la filosofía moderna precedente. Para citar un ejemplo que nos es ya familiar, pensemos en lo que más arriba se decía a propósito del tribunal de la conciencia, ante el que el sujeto moral se desdoblaba en juez y también legislador, por un lado, y en reo o acusado de violar su propia legislación moral, por otro. Semejante desdoblamiento respondía, según aclara el mismo Kant en nota al pie del párrafo antes reproducido, a la dualidad

${ }^{7}$ Véase sobre este punto mi trabajo «El retorno del sujeto moral en el pensamiento postmetafísico», en Problemas actuales de la ética (Actas del VIII Encuentro de la Sociedad Castellano-Leonesa de Filosofía, Salamanca, Noviembre de 1992), en prensa. 
del yo nouménico (homo noúmenon) y el yo empírico o fenoménico (homo phenómenon). Pero no hay, en rigor, necesidad de acudir a semejante duplicación metafísica del sujeto moral para dar cuenta de lo que ocurre con el tribunal de la conciencia. Como Aranguren ha hecho $\operatorname{ver}^{8}$, el sujeto moral es siempre un «in-dividuo» (individuum no es sino la traducción latina del griego átomos, que significa «indiviso»), pero, en tanto que sujeto moral, el individuo es también «dividuo», es decir, dividido en dos o dos en uno, que es lo que le permite desdoblarse -dentro de ese proceso de reflexión, de reflexión moral, que era para Platón «el diálogo del alma consigo misma»- en un ego y un alter destinados a oficiar de interlocutores en tal diálogo o, si quisiéramos decirlo echando mano de un par de pronombres personales, lo que le permite desdoblarse en un «yo» y en «tú» que deliberan.

Y la estrategia a seguir ahora con el problema de la libertad y la causalidad, cuyo protagonismo encomendaba respectivamente Kant al yo nouménico y al fenoménico, consistiría de nuevo en acudir a los pronombres personales -de la filosofía, y en concreto de la filosofía moral o de la ética, cabría decir lo que el poeta decía de la poesía, a saber, que también ella «vive en los pronombres»-, pero no esta vez los de primera y segunda persona, sino más bien los de primera y tercera persona. Cuando yo hablo de Fulano en tercera persona y digo que Fulano ha hecho esto o lo otro, nada me impide que le extienda lo que alguna vez he llamado el «beneficio de la causalidad», esto es, que trate de explicarme su conducta causalmente, atendiendo a los condicionamientos naturales (por ejemplo, su carácter o su temperamento) o a los condicionamientos sociales (por ejemplo, la educación que ha recibido o la clase social a la que pertenece), condicionamientos de los que la conducta de Fulano sería ahora interpretada como efecto, que es lo que hago al decirme, supongamos, que «Las circunstancias, naturales o sociales, obligan a Fulano a actuar como lo está haciendo» o que «Dadas la circunstancias, Fulano no tiene más remedio que actuar de ese modo». Pero lo que ya no me sería dado es hablar de mí mismo, en primera persona, de tal suerte, es decir, no me sería dado concederme a mí mismo semejante beneficio de la causalidad sin traicionarme moralmente e incluso dimitir de mi condición de sujeto moral, incurriendo de paso en lo que Sartre llamó la mauvaise foi y resultaría tal vez más apropiado llamar la «mala voluntad», la voluntad que tramposamente se engaña y cree poder rehuir el riesgo de la decisión, que es en definitiva el riesgo de la libertad (un imposible ético, como asimismo Sartre sabía bien, pues no cabe decidir no

${ }^{8}$ J. L. L. Aranguren, «La filosofía en la vida y la vida de la filosofía (Primeras Conferencias Aranguren)», Isegoría, 7, 1993, págs. 5-22, pág. 17. 
decidir sin decidir e incluso quien -ante opciones morales alternativas- dé en suspender su decisión, dejándose llevar por los acontecimientos, habrá ya decidido dejarse llevar por los acontecimientos, sólo que haciéndose la trampa de no querer reconocerlo así). A nadie, pues, le es dado decir de sí mismo «Soy un juguete de las circunstancias», pues acatar la imposición causal de las propias acciones por obra de las circunstancias ya es «tomar una decisión», cosa que no puede hacerse si no se hace libremente. Ahora bien, lo que acaba de afirmarse no corresponde tanto al mundo del «ser» cuanto al del «deber ser» -la segunda de las distinciones asociadas, recordemos, a la distinción kantiana entre libertad y causalidad-, mundo éste del deber ser que no es tampoco un ultramundo situado en parte alguna sino la expresión de nuestra insatisfacción con «lo que hay» en este mundo, unida a la aspiración de construir «lo que (creemos que) debiera haber» en él (una aspiración, nuevamente, embotada a menudo por la mala voluntad, toda vez que sin reconocernos en principio como libres sólo nos restaría el pasivo acatamiento de lo que hay, por insatisfactorio que nos pueda parecer). Comenzando, así pues, por nosotros mismos, nosotros no «debiéramos» traicionarnos nunca moralmente, no «debiéramos» nunca dimitir de nuestra condición de sujetos morales, no «debiéramos» incurrir jamás en la mala voluntad, pero lo cierto es que, de hecho, hacemos de ordinario todo eso que no debemos hacer, prestando así harto mayor fidelidad a lo que «somos» que a lo que creemos que «debiéramos ser». Y, en cuanto a esta segunda distinción entre el mundo del ser y el del deber ser, no sólo habría de permitimos distinguir a la ética respecto de la ciencia, sino asimismo respecto de la ontología -sino somos heideggerianos, no tendremos por qué distinguir entre una «ontología» y una «óntica», con lo que la ontología podría muy bien entonces concebirse como continua con la ciencia-, pues lo que diferencia de ellas a la ética es que esta última, según se acaba de indicar, no es un registro, ni científico ni ontológico, de lo que hay, sino una instancia desde la que someter a crítica eso que hay y, llegado el caso, disponernos por razones morales, que no causas, para hacer algo por cambiarlo.

Como a nadie se le oculta, el asunto de la libertad y la causalidad es bastante más complicado en el orden social que en el orden natural. Y de ahí la improcedencia de comparar la explicación de nuestras acciones ya sea con la de fenómenos meteorológicos como las nubes, ya sea con la de artefactos mecánicos como los relojes, improcedencia que subiría de tono si de la explicación científica o tecnológica pasásemos a la justificación moral de las mismas ${ }^{9}$. La

\footnotetext{
${ }^{9}$ Véase mi Presentación del libro de Amparo Gómez Sobre actores y tramoyas: la explicación situacional de la acción individual, Barcelona, 1992, págs. 7-15.
} 
causalidad natural, por mucho que a veces podamos controlarla con ayuda de la técnica, constituye un poder extraño ante el que en numerosas ocasiones nos sentimos impotentes y no tenemos otra alternativa que someternos: no somos libres para cambiar a nuestra voluntad las leyes de la naturaleza, y una alteración cromosómica o una lesión cerebral no sólo pueden restringir sino anular la libertad humana. También puede ocurrirnos esto último con la causalidad social, en especial por lo que se refiere a las llamadas «consecuencias inintencionadas» de nuestras acciones, de las que pueden derivarse y se derivan con profusión «efectos perversos» que, como la escoba del aprendiz de brujo, acaban escapando a nuestro control: ante el desencadenamiento de un proceso inflacionario podemos, en un momento dado, experimentar una impotencia comparable a la que experimentamos ante el desencadenamiento de un ciclón. Pero, en última instancia, tales efectos y consecuencias serán efectos y consecuencias de nuestras acciones por más que luego cobren vida propia, como por lo demás también sucede en no menor medida con las consecuencias intencionadas y los efectos no-perversos de la acción que cristalizan, por ejemplo, en instituciones sociales. Aun cuando la causalidad social pueda también determinarnos, e incluso nos determine en ocasiones con no menor compulsión que la causalidad natural, se tratará siempre de causas desencadenadas en última instancia por nosotros mismos. Por lo demás, no deja de ser cierto que la concepción más defendible de las «leyes (de las ciencias) sociales» -en la medida en que estas últimas no pasan de constituir, en el mejor de los casos, sino regularidades estadísticas más o menos precisas- guarda un mayor parecido con la moderna concepción indeterminista de las «leyes (de las ciencias) naturales» que con su concepción determinista clásica, pero, dejando a un lado el hecho de que el indeterminismo epistemológico no es lo mismo que la indeterminación ontológica, la indeterminación no es desde luego libertad, la cual se manifestará, antes bien, en aquella suerte de determinación no causal que conocemos como autodeterminación. Nosotros mismos, en tanto que sujetos morales, somos, qué duda cabe, un producto social, y no está claro que en otras épocas u otras sociedades menos evolucionadas los individuos se hallen en condiciones de autoconcebirse como sujetos morales a nuestra usanza, Pero, por más que nuestra propia subjetividad moral haya podido ser socialmente causada, lo habría sido con la particularidad de ser nosotros la causa remota de esas otras causalidades intermedias representadas por las prácticas sociales y su correspondiente cristalización institucional. Por lo demás, es innegable que dichas prácticas e instituciones sociales coartan nuestra libertad al menos tanto cuanto contribuyen a posibilitarla, llegando en ocasiones a asfixiar toda capacidad 
de autodeterminarse por parte de los individuos. Pero, aun si se tratase de un empeño destinado a la postre a fracasar, estaría siempre en nuestra mano la posibilidad de hacer algo por cancelar aquella ciega necesidad que hemos contribuido a establecer, necesidad que ha merecido la expresiva denominación de síntesis de la fatalidad y ha sido compendiada en el proverbio chino «Cuando la flecha está en el arco, tiene que partir» ${ }^{10}$ : cuando la flecha está en el arco, tiene que partir fatalmente en virtud de los usos sociales, usos bélicos por ejemplo, que -una vez instituidos- pueden llegar a funcionar de forma tan inexorable como los instrumentos de marras, el arco y la flecha mismos, que al igual que aquéllos han sido creación nuestra. Mas, en rigor, la flecha únicamente tiene que partir si a semejante imperiosidad no le oponemos nuestra convicción de que no debe ser disparada. Que es lo que, a fin de cuentas, abre paso a la disruptiva introducción de la libertad en la vida de la sociedad por la vía de la decisión moral.

Aunque el tribunal de la conciencia parecía quedar un poco lejos a estas alturas, lo que hemos hecho hasta el momento no ha sido sino devanar algunas de las implicaciones contenidas en aquella metáfora. Por ejemplo, las relativas a la libertad de decisión del sujeto moral en que acabamos de estarnos demorando. Pero va siendo ya hora de que, al menos, digamos unas palabras acerca de la segunda parte de nuestro título, esto es, acerca de la conciencia del tribunal.

Para empezar por ahí un tanto abruptamente, podríamos ahora preguntarnos qué pasa con las leyes jurídicas en cuanto diferentes de las leyes naturales es decir, las leyes de las ciencias naturales) y las leyes sociales (es decir, las leyes de las ciencias sociales). Cuando hablo de las «leyes jurídicas» no estoy hablando, por lo pronto, de las «leyes de la Ciencia del Derecho», cualquier cosa que sea lo que tan pintoresca expresión quiera decir, sino sencillamente de las «leyes del Derecho», esto es, las leyes recogidas en los ordenamientos jurídicos. Y un sumario cotejo de esas leyes y las llamadas «leyes naturales» bastaría a poner de manifiesto lo desdichado de la invocación iusnaturalista de una supuesta ley natural que estaría ciertamente lejos, ni lo pretenderían así los iusnaturalistas, de podérsenos imponer por vía causal. Como lapidariamente escribiera Rousseau, «la naturaleza no produce derecho alguno», ni siquiera, añadamos, Derecho Natural, que, como tantas veces se ha dicho, tiene bastante poco de «derecho» y menos aún de «natural». En cuanto al cotejo de las leyes jurídicas con las llamadas «leyes sociales»,

${ }^{10}$ Cfr. Rafael Sánchez Ferlosio. «Cuando la flecha está en el arco, tiene que partir», en J. M. González-C. Thiebaut (eds.), Convicciones políticas, responsabilidades éticas (V Semana de Ética y Filosofía Política), Barcelona, 1990, págs. 245-78. 
reviste, desde luego, mayor complejidad, pero el criterio de distinción entre unas y otras vendría a ser similar al anterior, dado que las leyes sociales, si las hay, se nos impondrán asimismo por vía causal, mientras que la coacción jurídica nada tiene que ver con la imposición de una causalidad. La prueba de ello es que las leyes jurídicas podrán ser desobedecidas -en España contamos con una nutrida bibliografía sobre el tema de «la desobediencia al Derecho», inaugurada en su día por un magistral ensayo del profesor Felipe González Vicén ${ }^{11}$-, pero carece en cambio de sentido hablar de desobedecer las leyes del mercado dentro del marco de una economía capitalista, pues la desobediencia a ellas no les resta eficacia causal, como lo haría patente la ruina de quien se arriesgue a desobedecerlas. Quien desee oponerse a aquellas leyes lo que tiene que hacer no es desobedecerlas, sino tratar de corregir el funcionamiento del sistema económico de mercado y hasta de acabar con el capitalismo, cosa, por todos los indicios conocidos, bastante más difícil de hacer que de decir, lo que no implica que no quepa intentarlo con mejor tino o con mayor fortuna que hasta ahora. En cuanto al ejemplo del arco y de la flecha que antes veíamos, lo propuse deliberadamente allí en virtud de su ambigüedad, pues la actitud del arquero que se negase a disparar podría responder tanto a su oposición a una ley social cuanto a su oposición a una ley jurídica. En el primero de ambos casos, las guerras acostumbran a estallar sobre la base de una serie de condicionamientos que discurren desde la existencia de ejércitos e industrias de armamentos a la vigencia de una mentalidad agresiva en capas más o menos amplias de la población, y tratar de contrarrestar la eficacia concertada de todas esas concausas a golpe de desobediencia quizás no contribuyera más al fomento de la paz de lo que la desobediencia a las leyes del mercado contribuiría a la prosperidad económica del desobediente; pero si de lo que se trata es de desobedecer una ley jurídica como la que regula la prestación del servicio militar, entonces sí que tendría sentido desobedecerla e incluso tal desobediencia podría luego repercutir por vía causal en el sistema social mismo, contribuyendo, por ejemplo, a minar la solidez de las fuerzas armadas o a incrementar la propagación de movimientos pacifistas. En ocasiones, esa desobediencia descansa en «objeciones de conciencia», lo que remite al tribunal de la conciencia del objetor, si bien lo que nos interesa ahora no es ya, como anunciamos, el «juez» de la conciencia sino por el contrario la «conciencia» del juez. Como tampoco

${ }^{11}$ F. González Vicén, «La obediencia al Derecho», recogido en su libro Estudios de Filosofía del Derecho, La Laguna, 1979, págs. 365-98 (para un resumen hasta la fecha de semejante discusión, en curso todavía, cfr. Juan Ramón de Páramo, «Obediencia al Derecho: revisión de una polémica», Isegoría, 2, 1990, págs. 153-61). 
sería ahora nuestro tema, aunque obviamente lo incluya, el del pronunciamiento de los jueces ante el quebrantamiento de la ley por motivos de conciencia de parte de los encausados, como en el caso de ese paso más sobre la objeción de conciencia que se conoce con el nombre de insumisión y se traduce en la negativa a cumplir la prestación sustitutoria del servicio militar legalmente prevista para los objetores.

La absolución hace algún tiempo de un «insumiso» en nuestro país levantó una considerable polvareda polémica de la que quedarán, cuando se sedimente, valiosas contribuciones de algunos destacados filósofos compatriotas del Derecho ${ }^{12}$ que me excusan de entrar en la cuestión. Y en relación con este punto, por lo tanto, me limitaré a señalar que estoy de acuerdo con Hans Welzel cuando afirma que «obrar en conciencia» no es lo mismo que «obrar como es debido» ni tan siquiera desde un punto de vista moral, a lo que, no obstante, añadiría que -aun cuando nadie pueda nunca tener la seguridad de estar haciendo lo que moralmente debiera- hacer lo que en conciencia cree que debe hacer es lo más lejos que un individuo puede ir cuando pretende cumplir con su deber moral, por lo que, en lo tocante a tal deber, no alcanzo a divisar otra instancia por encima de la conciencia individual. Naturalmente, la situación es muy distinta por lo que se refiere al cumplimiento de un deber legal, pero tampoco aquí sabría decir si acierta Welzel cuando, en el capítulo de su libro Más allá del Derecho natural y del Positivismo jurídico dedicado a «La ley y la conciencia» ${ }^{13}$, rechaza bienintencionadamente la cruda

concepción de la norma jurídica como una «norma coactiva de carácter heterónomo» para abogar por la «obligatoriedad en conciencia del orden jurídico dotado de validez normativa» que se supone que el individuo habría de internalizar autónomamente -¿pero dónde está entonces el conflicto entre la ley la conciencia que motivaba nuestra consideración?-, obligatoriedad en conciencia del orden jurídico que sería para Welzel «lo que distingue al Derecho de la fuerza». Pese a lo cual la fuerza vendría luego a apoyar al Derecho -como no cabía menos que esperar, se me ocurre- a la hora de «imponer coactivamente la realización de aquel orden jurídico» que la obligación en conciencia de acatarlo por parte de los individuos no alcanza, por lo visto, a asegurar. Aunque Welzel no es insensible a la «tensión», a veces trágica, que subsiste entre la ley y la conciencia ${ }^{14}$,

\footnotetext{
${ }^{12}$ Cfr., a título de muestra, las contribuciones de María José Añón, Rafael de Asís, José María Contreras, Eusebio Fernández, José Manuel Gómez Benítez, Javier de Lucas, Gregorio Peces-Barba, Luis Prieto, Alfonso Ruiz Miguel y Ernesto Vidal a G. Peces-Barba (ed.), Ley y conciencia, Madrid, 1993.

${ }^{13}$ H. Welzel, Naturrecht und Rechtspositivismus, Aquisgrán, 1959 (hay trad. cast., por la que cito, de E. Garzón Valdés, Córdoba, Argentina, 1962, págs. 65-103).

${ }^{14}$ Ibíd., especialmente págs. 88 y ss. (Para un juicio más ponderado que el esbozado aquí sobre la posición de Welzel, véase la Introducción de Ernesto Garzón Valdés, «El pensamiento jurídico de Hans Welzel», a la traducción de la obra de este último citada en la nota precedente).
} 
se diría que su mayor preocupación se endereza en definitiva a apaciguarla, lo que francamente no me parece deseable.

No me parece, insisto, deseable tratar de apaciguar la tensión, o el conflicto, entre la conciencia moral y la ley jurídica: esa tensión no es infecunda -permite, entre otras cosas, que se redacten papeles como éste-, probablemente sea inapaciguable y lleva, en cualquier caso, abierta muchos siglos, por lo menos desde su dramatización a manos de Antígona y Creonte, como para dar en cerrarla ahora con prisas y a destiempo. (Que no nos pase como en aquella anécdota que contaba un escritor español poco agraciado aunque gracioso a ratos -José María Pemán- en relación con el estreno de su versión del Edipo de Sófocles, para lo que no se le ocurrió cosa mejor que invitar a su palco a un general de infausta memoria por su brutalidad y escasas luces, que fue durante muchos años, y lo era a la sazón, Ministro de Gobernación bajo la dictadura franquista. Conforme la representación avanzaba, el invitado se iba poniendo cada vez más nervioso y excitado hasta que, en un momento dado, no pudo contenerse por más tiempo y aferró bruscamente el brazo del autor, exclamando con los ojos fuera de las órbitas «Pero, Pemán, este hombre está casado con su madre!», a lo que Pemán, tratando como fuera de salir del trance, respondió «Tranquilícese usted, mi General, que lleva así unos cuantos siglos ya». Como el aciago matrimonio de Edipo y de Yocasta, también el enfrentamiento de Antígona y Creonte es un enfrentamiento secular, por lo que no resulta aconsejable tratar de resolverlo de hoy para mañana y sería mejor dejarlo estar).

Pero vayamos ya con «la conciencia del tribunal» o de los jueces. Si comparamos la conciencia del juez con la conciencia del sujeto moral que intervenía en la metáfora kantiana del comienzo, apreciaremos, por lo pronto, una importante diferencia. La conciencia del juez, como la de cualquier mortal, puede no menos desdoblarse -desde un punto de vista moral- en juez (y autolegislador), por un lado, y en acusado por el otro; pero en tanto que juez -esto es, desde un punto de vista jurídico- no hay evidentemente tal desdoblamiento, el juez no ocupa aquí el banquillo del acusado (aunque pueda, sin duda, «ponerse en su lugar» a los efectos de comprender la conducta de este último) y, lo que para nosotros es más importante, tampoco es ya legislador (para decirlo recurriendo de nuevo a los pronombres personales, la ley con la que el juez ha de juzgar ya no procede de su «yo», sino del «nosotros» de la comunidad, o de la sociedad, o del 
Estado en cuyo nombre juzga, un nosotros que -en un régimen de democracia más o menos representativa y con división de poderes- encarnará en los órganos, el Parlamento por ejemplo, que usufructúan el poder legislativo). Por descontado, el juez como persona es sólo uno, como una sola en su conciencia, pero las decisiones que el juez tome desde esa su conciencia se verán constreñidas por la ley ajena a ella que tiene que aplicar. Nos encontramos, así pues, ante el caso realmente singular de un sujeto que -sin dejar de ser por ello un sujeto moral- podría tal vez decir, sin incurrir en «mala fe» (esto es, en mala voluntad), «No me es dado actuar de otra manera» o, con otras palabras, «No soy libre de decidir sino dentro de los límites que me marca la ley», donde las constricciones impuestas por esta última ya no operarían por vía causal (como en los casos que antes vimos de las leyes naturales o sociales), sino serían, estrictamente hablando, constricciones jurídicas, las constricciones, por así decirlo, del imperio de la ley (para muchos, ahí residiría la grandeza y la servidumbre de la judicatura, y a eso vendría por tanto a reducirse el problema de la conciencia del juez). Pero teniendo en cuenta que el juez es, como se ha dicho, un sujeto moral, ¿cabe pensar que, de esa suerte, se hayan acabado sus problemas? ¿Cabe pensar que un juez no tenga «problemas de conciencia», o no será más bien que el problema de la conciencia del juez, dado por resuelto con tanto apresuramiento, comienza justamente a partir de este punto?

Naturalmente, la cuestión ni tan siquiera se suscitaría si admitiésemos -como hoy, por fortuna, está ya lejos de admitirse, siquiera con el grado de generalización que en otros tiempos- la concepción extremadamente formalista de la aplicación del Derecho según la cual la decisión jurídica se sigue lógicamente (esto es, de acuerdo con los patrones de inferencia de la lógica deductiva) y sin problemas (problemas, por lo pronto, hermenéuticos o de interpretación de los textos legales, pero también, según se ha dicho, problemas prácticos y en última instancia morales, como los relativos a la justicia de la decisión) de las formulaciones de las normas que hay que presuponer como vigentes ${ }^{15}$. El juez no es, en efecto, un ergo, es decir, una partícula ilativa cuya única función sea conectar unas premisas con una conclusión dentro de un silogismo, como en el caso del llamado «silogismo judicial» que se limita a derivar, al menos en apariencia, una sentencia a partir de una norma o conjunto de normas, tras de la subsunción de los hechos relevantes bajo el supuesto regulado por la ley. Como ha mostrado Manuel Atienza en su excelente

${ }^{15}$ Cfr. la pormenorizada problematización de la normatividad jurídica llevada a cabo por Juan Carlos Bayón en la Introducción a su libro La normatividad del Derecho: deber jurídico y razones para la acción, Madrid, 1991, págs. 17-45. 
libro Las razones del Derecho ${ }^{16}$, la propia lógica formal deductiva ha flexibilizado en tal contexto la angostura de su rigor hasta desembocar en una serie de teorías de la argumentación jurídica, que es precisamente el subtítulo del libro (las más acreditadas de entre esas teorías se moverían en un espacio intermedio que discurre desde el ultrarracionalismo de un Ronald Dworkin -cuyo juez Hércules hace gala de una envidiable confianza en la capacidad de su razón- hasta el irracionalismo de un Alf Ross, si merece tacharse de irracionalista su realista llamada de atención sobre el hecho de que las decisiones jurídicas, al igual que sucedería con cualquier otro género de decisión, dependen de la voluntad del sujeto de las mismas -en este caso, el juez- al menos tanto como de su razón).

En opinión de Dworkin, la argumentación jurídica tendría que conducir en cualquier caso -incluidos los llamados «casos difíciles», en los que se tropieza con la dificultad de dar con una norma que resulte aplicable al caso- a una única respuesta correcta, que acaso el juez real no sea capaz de encontrar pero que, al menos idealmente, se hallaría al alcance de las portentosas facultades de Hércules. El problema es, no obstante, que las razones jurídicas «suelen salir a pasear»-como alguna vez se ha dicho- «por parejas», cuando no en grupo o en manada, y el mismísimo Hércules podría tenerse que enfrentar a más de una respuesta correcta entre las cuales se viera obligado a elegir ${ }^{17}$. Y ello por no pensar, como también ha sido sugerido, en la posibilidad de dos o más jueces Hércules con respuestas incompatibles o contradictorias para un mismo caso difícil. En semejantes circunstancias de indeterminación jurídica, Herbert Hart ha opinado que no habría otro remedio que encomendar tal caso a la discrecionalidad de un juez, aunque éste no sea hercúleo, a lo que ha respondido Dworkin que eso equivaldría a conceder a dicho juez la indeseable potestad de «crear Derecho», algo a lo que, a decir verdad, no haría ascos el «voluntarismo» de Ross, como no se lo hizo en el pasado el voluntarismo jurídico de la llamada «Escuela del Derecho libre ${ }^{18}$. Ahora bien, el problema -el problema del voluntarismo jurídico- pasa entonces a ser el de los límites de esa «creación del Derecho» por parte de los jueces, pues concebir a ésta como irrestricta equivaldría a conceder al juez la potestad absoluta que el voluntarismo teonómico medieval, y luterano, concedía a Dios al sostener que lo que Dios quiere no lo quiere por ser justo

\footnotetext{
${ }^{16}$ M. Atienza, Las razones del Derecho (Teorías de la argumentación jurídica), Madrid, 1991.

${ }^{17}$ Cfr. Neil MacCormick, Legal Reasoning and Legal Theory, Oxford, 1978, págs. 265 y ss.

${ }^{18}$ Ibíd., así como, del mismo autor, H. L. A. Hart, Londres, 1981.
} 
sino más bien es justo por quererlo Dios, un hoc volo sic iubeo, sit pro ratione voluntas, para decirlo con Juvenal, que aproximaría peligrosamente al juez terrenal a la figura del dictador.

La irrupción de la teología en este contexto no es casual ni está traída por los pelos, pues no sólo el extremo voluntarismo, sino también el racionalismo extremo, son en definitiva secularizaciones jurídicas ya de la omnipotencia, ya de la omnisciencia de la Divinidad. En el texto de Kant al que aludíamos al comienzo, se consideraba la posibilidad de que el juez del tribunal de la conciencia no fuera más que una transposición de la idea de Dios al terreno de la razón práctica ${ }^{19}$, y el omnisciente juez Hércules de Dworkin pertenece asimismo a esa progenie secularizada de un Juez Supremo ideal, propensión ésta idealizante de la que ni siquiera se ven libres las que antes llamábamos «teorías más acreditadas de la argumentación jurídica» ${ }^{20}$ : así parece probarlo, pongamos por ejemplo, el recurso de un Neil MacCormick a la instancia de un Espectador Imparcial como criterio ideal de decisión coherente o consistente ${ }^{21}$; o la socialización de ese sujeto ideal en lo que la Retórica de Chaim Perelman da en llamar un Auditorio Universal, esto es, un hipotético auditorio cuya hipotética adhesión permitiría hipotéticamente contrastar la fuerza de los $\operatorname{argumentos}^{22}$; o, finalmente, la invocación de un Consenso Ideal llevada a cabo por la Teoría del Discurso de Robert Alexy, que delata un mismo aire de familia, exacerbado esta vez, si cabe, por su proclamado parentesco habermasiano ${ }^{23}$. Pues tal consenso ideal es presentado allí, siguiendo a Habermas, como un ideal regulativo de corrección idealmente destinado a recompensar las pretensiones de validez (Geltungsansprüche) del discurso jurídico en tanto que un subapartado del discurso práctico en general y, por consiguiente, del discurso moral.

Como Atienza ha visto muy bien, esta última incrustación del Derecho en la Moral constituye una idealización añadida, una idealización, en este caso, particularmente arriesgada, pues podría contribuir a difuminar la frontera que separa, y está bien que lo haga, al Derecho sin más del Derecho justo ${ }^{24}$. Y la contrapartida, no menos improcedente, de semejante difuminación de fronteras consistiría a

${ }^{19}$ Kant, Metaphysik der Sitten, cit., pág. 439.

${ }^{20}$ Véase el tratamiento que les dispensa Atienza, op. cit., cc. III, V y VII.

${ }^{21}$ Ibíd, págs. 131 y ss., esp. 175-6.

${ }^{22}$ Págs. 65 y ss., esp. 89-91.

${ }^{23}$ Págs. 177 y ss., esp. 210-6.

${ }^{24}$ Como advierte Atienza a propósito de la Theorie der juristischen Argumentation de Robert Alexy (Francfort del Main, 1978; hay trad. cast. de M. Atienza e I. Espejo, Madrid, 1989), «el Derecho contiene para Alexy una dimensión ideal que lo conecta, en forma conceptualmente necesaria, con una moralidad procedimental y universalista» (op. cit., pág. 203). 
continuación en echar mano de la ética para extender un manto de legitimidad sobre la simple legalidad del Derecho positivo ${ }^{25}$, por más que este Derecho sea -así para Alexy como para el resto de los teóricos de la argumentación jurídica considerados- el Derecho de un auténtico Estado de Derecho, esto es, constitucional y democrático. Por eso, en medio del sofocante clima generado por tanta idealización, me parecen sumamente oportunas, saludables y estimulantes las observaciones con las que Atienza cierra su repaso de las teorías de la argumentación jurídica, preguntándose por el tipo de ideología -de ideología jurídica- que se halla a la base de las mismas ${ }^{26}$ : «...(Alexy) parte de una valoración esencialmente positiva de lo que es el Derecho moderno -el Derecho de los Estados democráticos- y de la práctica de su interpretación y aplicación. Aunque (Alexy) difiere de Dworkin... en cuanto que no acepta la tesis de que para todo caso jurídico existe una sola respuesta correcta, sigue considerando -como Dworkin- que el Derecho positivo proporciona siempre, cuando menos, una respuesta correcta. En definitiva, el presupuesto último del que parte es el de que siempre es posible «hacer justicia de acuerdo con el Derecho». Ahora bien, en mi opinión, la teoría de la argumentación jurídica tendría que comprometerse con una concepción -con una ideología política y moral- más crítica con respecto al Derecho de los Estados democráticos, lo que, por otro lado, podría suponer también adoptar una perspectiva más realista. Quien tiene que resolver un determinado problema jurídico, incluso desde la posición del juez, no parte necesariamente de la idea de que el sistema jurídico ofrece una solución correcta -política y moralmente correcta- del mismo. Puede muy bien darse el caso de que el jurista -el juez- tenga que resolver una cuestión y argumentar en favor de una decisión que es la que él estima como correcta aunque, al mismo tiempo, tenga plena conciencia de que ésa no es la solución a que lleva el Derecho positivo. El Derecho de los Estados democráticos no configura necesariamente «el mejor de los mundos jurídicamente imaginables (Atienza reproduce aquí literalmente una brillante e hiriente frase de Ernst Tugendhat dirigida contra la construcción teórica de Alexy ${ }^{27}$, aunque sí que sea el mejor de los mundos jurídicos

${ }^{25}$ Así lo refleja, ya en su título, el conocido texto de Jürgen Habermas, «Wie ist Legitimität durch Legalität möglich?», Kritische Justiz, 20, 1987, págs. 1-16, posteriormente recogido en el apéndice (Vorstudien und Ergänzungen) a su libro Faktizität und Geltung. Beiträge zur Diskurstheorie des Rechsts und des demokratischen Rechtsstaats, Francfort, 1993 (hay trad. cast. de M. Jiménez Redondo, en preparación).

${ }^{26}$ M. Atienza, op. cit., págs. 251-2.

${ }^{27}$ E. Tugendhat, «Zur Entwicklung von moralischen Begründungstrukturen in modernen Recht», Archiv für Rechts- und Sozalphilosophie, 14, 1980, págs. 1-20, pág. 4. 
existentes... (Pero) la práctica de la adopción de decisiones jurídicas mediante instrumentos argumentativos no agota el funcionamiento del Derecho, que consiste también en la utilización de instrumentos burocráticos y coactivos. E incluso la misma práctica de argumentar jurídicamente para justificar una determinada decisión puede implicar en ocasiones un elemento trágico (en otro lugar, y en otros textos, Atienza ha denominado «casos trágicos», en cuanto diferentes de los «casos fáciles» pero también de los «casos difíciles», a aquéllos en los cuales no existe ninguna respuesta correcta, viniendo a constituir, por tanto, casos que «no se pueden decidir si no es vulnerando el ordenamiento jurídico») $»^{28}$.

Y son esos casos trágicos, entre otros, los que por excelencia plantean problemas de conciencia a los jueces y tribunales, como trágico es el conflicto entre la ley y la conciencia, entre el Derecho y la justicia, entre el ser jurídico o legal y el deber ser político o moral.

En un libro de Pietro Barcellona que acaba de traducirse al castellano ${ }^{29}$, aquél escribe que el sentido de la tragedia es necesario para preservar la tensión entre el Derecho y la justicia. Y, si traigo su libro a colación, es porque Barcellona fue en su día un conspicuo representante de aquel movimiento iusfilosófico que se acogiera bajo el rótulo por entonces prometedor del «uso alternativo del Derecho». Desde un marxismo crítico, y autocrítico, sus adherentes trataron de corregir la proverbial desconsideración del Derecho en dicha tradición de pensamiento y -persuadidos de que las prácticas jurídicas nacen al calor del conflicto de los intereses sociales y se desarrollan inmersas en tal conflicto- pretendieron valerse del Derecho para contribuir a la transformación política de la sociedad en una dirección más justa: el progresivo derrumbe del marxismo europeo, con el consiguiente descrédito de su producción teórica, se llevó al movimiento consigo en la nada y hoy ya no se habla apenas

${ }^{28}$ M. Atienza, op. cit., pág, 232; cfr., asimismo, «Sobre lo razonable en el Derecho», Revista española de Derecho Constitucional, 27, 1989, págs. 93-110 y Tras la Justicia (Una introducción al Derecho y al razonamiento jurídico), Barcelona, 1993, págs. 136 y ss., 177-80, donde -a propósito del «caso del insumiso» más arriba aludido- escribe que «los jueces (o, al menos, algunos jueces) no se enfrentan aquí con un simple problema de elección entre diversas soluciones alternativas, sino con un verdadero dilema: o sacrifican el principio de legalidad y de subordinación del poder judicial al legislativo, o sacrifican el principio de libertad de conciencia, de proporcionalidad de las penas, de exclusiva protección penal de bienes jurídicos, etc.; todavía más simple: o hacen justicia, o aplican la ley».

${ }^{29} \mathrm{P}$. Barcellona, Postmodernidad y comunidad: el regreso de la vinculación social, trad. de $\mathrm{H}$. C. Silveira-J. A. Estévez-J. R. Capella, Madrid, 1993, pág. 93. 
de é $\mathrm{l}^{30}$. Tengo para mí que se trató de un infortunio en buena parte inmerecido, pues su suerte, en cualquier caso, no merecía estar ligada a la del «socialismo real», al que la mayoría de los miembros del movimiento siempre consideraron bastante más «real» que «socialista». En cuanto a un superviviente como Barcellona, se muestra en este libro más como un filósofo político que como un iusfilósofo, consciente, por ejemplo, de que la protección jurídica de la infancia y la ancianidad, por acudir a dos ilustraciones capaces de excitar nuestros buenos sentimientos, y en general la protección de esos derechos humanos que son los derechos económicos y $\operatorname{sociales}^{31}$, no avanzará gran cosa si no se actúa enérgicamente sobre las estructuras sociales en que anida y se perpetúa la injusticia, esto es, si no se actúa sobre la esfera de lo que más arriba hemos llamado la causalidad social.

Pero la sensibilidad para «lo trágico» pervive al menos hoy, en otra corriente de pensamiento jurídico tan distinta de aquélla como distante, y no sólo en el tiempo sino asimismo en el espacio, pues la separa de Europa nada menos que el océano Atlántico. Me refiero al movimiento conocido con el nombre de Critical Legal Studies y desarrollado en los Estados Unidos desde otras tradiciones intelectuales que las europeas, aunque en la formación originaria de algunos de sus representantes no falten ramalazos de una cierto neomarxismo sesentayochista ${ }^{32}$. Por lo que a mí respecta, y para concluir, quisiera referirme al tratamiento que uno de los más cualificados líderes de tal corriente, Duncan Kennedy, de la Harvard Law School, dispensa a lo que dimos en llamar un «caso trágico».

El texto que contiene su examen de este último se titula «Libertad y constricción en la aplicación judicial de la ley o el Derecho» -por traducir mediante un circunloquio el término adjudication, tan intraducible como lo suelen ser los procedentes del common law, anglosajón- y lleva por subtítulo el de «Una fenomenología crítica», aun cuando constituye, para precisarlo todavía más, un ejercicio de análisis o «autoanálisis existencial», no siendo extraño que Sartre aparezca

${ }^{30}$ Del eco que tuvieron en España sus propuestas dan testimonio las simpacéticas alusiones de Elías Díaz en su libro Legalidad-legitimidad en el socialismo democrático, Madrid, 1978, págs. 54, 68, 127-8, 187 y ss., y el volumen colectivo de Nicolás López Calera, Modesto Saavedra y Perfecto Andrés Ibáñez, Sobre el uso alternativo del Derecho, Valencia, 1978.

${ }^{31}$ Barcellona, op. cit., págs. 105 y ss.

${ }^{32}$ La muy interesante tesis doctoral del profesor de la Universidad de Alicante Juan Antonio Pérez Lledó, El movimiento «Critical Legal Studies», que espero ver pronto publicada, insiste incluso en conectarlo con la Teoría Crítica francfortiana, aun cuando en su opinión se trata de una corriente polimorfa que responde a otras muchas y muy diversas influencias, desde el realismo jurídico americano al pensamiento postmoderno. 
citado entre las fuentes de la bibliografía introductoria de nuestro paper $^{33}$. El ensayo de Kennedy, entrando ya en él, trata de describir el proceso del razonamiento legal de un juez que se debate en el conflicto entre la ley y su pregunta acerca de «cómo salir del paso» (how I want to come out). La pregunta puede asaltarle al juez por una diversidad de motivos, como, por ejemplo, el hecho de haber aceptado un previo soborno y la necesidad en que se halla de mantener el trato, o el deseo de hacerse popular dentro de su comunidad -sea la comunidad vecinal, sea la comunidad profesional-, o también, ¿por qué no?, la repugnancia que le inspira la obligación que recae sobre él de tener que aplicar una disposición legal contraria a sus convicciones. En cualquiera de esas hipótesis, se produce un choque entre la ley y sus preferencias personales, lo que no es sino otro modo de decir que todo juicio de un juez ha de ir inevitablemente precedido, lo sepa y quiera el juez o no, de un pre-juicio que contribuye a ponerlo en situación. En la hipótesis que Kennedy elige, se tratará del juez de una corte federal que discrepa de la ley a aplicar por motivos de ideología política. Y, aunque por razones de estilo y conveniencia nosotros hablaremos de «el juez», el análisis o autoanálisis en que el texto consiste emplea todo el rato el pronombre «yo», es decir, en él se habla invariablemente en primera persona, lo que sabemos ya que no es indiferente para el caso, pues revela, en efecto, que nos enfrentamos a un dilema moral. Simplificando mucho la descripción del asunto, el juez se encuentra ante una huelga de conductores de autobuses, cuya compañía los ha sustituido en el curso de la negociación de un convenio por esquiroles ajenos al sindicato; los miembros de éste reaccionan organizando sentadas delante de la estación de autobuses, sentadas pacíficas que no obstaculizan el tráfico en la calle pero impiden salir de las cocheras a los vehículos de la compañía; la policía local arresta a los manifestantes bajo el cargo de alterar el orden público, pero al día siguiente nuevos manifestantes vuelven a obstruir la salida, con similares resultados; los autobuses circulan, pero con considerables retrasos y en medio del caos generalizado; la situación, en fin, se va tornando poco a poco insostenible. La compañía entonces se dirige a la corte federal solicitando un interdicto (una injunction, en la jerga del common law). Y así comienzan las cuitas (troubles) del juez que nos ocupa ${ }^{34}$.

${ }^{33}$ D. Kennedy, «Freedom and Constraint in Adjudication: A Critical Phenomenology», Journal of Legal Education, 36, 1986, págs. 518-62 (una versión abreviada del texto ha sido publicada en el volumen de A. Hutchison y P. Monahan, eds., The Rule of Law: Ideal or Ideology, Toronto, 1986).

${ }^{34}$ Otra buena manera de describir la situación consistiría en denominarla un «rompecabezas» (puzzle), que el autor no vacila en rotular por medio de las siglas HIWTCO (acrónimo de «how I want to come out»). 
En principio, la ley parece favorecer sin reservas a la compañía, pero el juez no considera correcto que ésta pueda continuar prestando sus servicios con la ayuda de un nuevo personal contratado en tanto se halla abierto el proceso negociador con los huelguistas. Es un juez progresista al que le gustaría rehusarse a la emisión del interdicto, pues ha leído con aprobación los trabajos del profesor Roberto Mangabeira Unger ${ }^{35}$ acerca de la «vocación de transformación social» del jurista que se resiste a hacer el juego a los grupos detentadores del poder y aboga por servirse de la ley con vistas a promover una organización más igualitaria y participativa de la sociedad. Mas se siente, no obstante, «constreñido» por esa ley que le consta que no puede «aplicar» a su entera «discreción». A partir de semejantes consideraciones, el juez inicia un tortuoso recorrido -que, por supuesto, voy a ahorrarle al lector- a través de los entresijos de la maraña legal, buscando construir un argumento que le permita encontrar una salida de acuerdo con sus designios. La ley no es vista como algo que le constriña en el sentido de dictarle lo que ha de hacer. $\mathrm{Su}$ constricción, más bien, es la de un medio en el que el juez ha de desenvolverse y llevar adelante su proyecto sirviéndose de recursos legales, algo así como el aire cuya resistencia permite volar a la paloma, pero sin por lo demás indicarle la dirección en la que ésta podría orientar su vuelo. A lo largo del trayecto, se unen a las motivaciones jurídicas y/o políticas del juez motivaciones psicológicas no menos poderosas, como el temor a quedar mal (por ejemplo. ante la ulterior corte de apelación de su fallo) o la aspiración a quedar bien, ya sea ante sus amigos o ante sus enemigos y tanto si falla a favor de los huelguistas (que lo verían como un hombre que antepone sus ideales a cualquier otra consideración) como si lo hace a favor de la compañía (en cuyo caso sería visto como un hombre para el que el peso de la ley cuenta en definitiva más que sus opiniones personales). La resolución óptima del conflicto sería aquélla que permitiera dar satisfacción a todas esas motivaciones mediante el hallazgo de un buen argumento, un argumento que haga exclamar a la gente «Nunca pensé que me pudiera convencer de tal cosa»o, al menos, «No me ha convencido, pero me ha dado que pensar y obligado a tomarme en serio el asunto». La resolución pésima del mismo consistiría en tener que fallar en contra de la propia conciencia. O a favor de ella pero sin argumentos o valiéndose de argumentos falaces. En resumidas cuentas, pues, la disyuntiva del juez estribará en decirse a sí mismo que «la ley es la ley» y no darle más vueltas o

\footnotetext{
${ }^{35}$ A. R. Mangabeira Unger, considerado él mismo una figura dentro del movimiento, se le debe una importante reflexión sobre este último. The Critical Legal Studies Movement, Cambridge, Mass., 1986.
} 
ver en ésta un instrumento para «hacer justicia», lo que quiere decir hacer aquello que cree justo en conciencia. A no rehuir tal disyuntiva le compromete su lectura de Max Weber ${ }^{36}$, que le induce a hacer honor al weberiano "pacto con el diablo» contraído en su calidad de funcionario de la Administración. Y aunque entre una y otra de aquellas dos alternativas queda sin duda un amplio margen de flexibilidad, maleabilidad y manipulabilidad de la ley, lo que está claro para desolación del juez es que la ley no es infinitamente flexible, maleable ni manipulable.

He aquí, por consiguiente, cómo nuestro atribulado juez compendiaría las posibles «salidas» del atolladero ${ }^{37}$.

Primera, ajustarse a la ley. A despecho de su convicción de que ésta es injusta, el juez emite el interdicto y acompaña su fallo de un informe denunciando la ley y urgiendo su reforma, aun a sabiendas de que sus recomendaciones serán con toda probabilidad desatendidas (la cuestión crucial, se confiesa a sí mismo en semejante tesitura, es cómo explicarle a su conciencia que aquel fallo le convierte en cómplice de una injusticia).

Segunda, abandonar el caso. El juez ni emite el interdicto ni lo deniega, alegando que a su conciencia le repugna por igual saltarse la ley a la torera que fallar de manera manifiestamente injusta, en cuyo caso la cuestión crucial vendría ahora a ser cómo el juez justifica ante sí mismo el hecho de pasarle a otro la patata caliente del trabajo sucio (naturalmente, no todos los casos trágicos son igualmente trágicos ni la repugnancia que inspira una determinada ley tiene por que extenderse a la totalidad del ordenamiento jurídico en su conjunto, pero imagino que si nuestro juez se hubiera visto forzado a aplicar una ley racial en la Alemania nazi, lo más probable sería que abandonase no ya el caso, sino la profesión, y podría por añadidura ahorrarse los escrúpulos de compañerismo para con los colegas que le sucedan en su puesto).

Tercera, decidir contra el interdicto sobre la base de lo que la ley debiera ser. El juez deniega el interdicto, explicando honestamente su incapacidad de encontrar «un argumento jurídico plausible» en contra de la ley tal como es y asumiendo la posibilidad o, mejor dicho, la seguridad de que la sentencia sea revocada por un tribunal de orden superior, así como las consecuencias que de todo ello se deriven para su crédito en la profesión. Además de ello, el juez podrá alegar que así es como fallaría en cualesquiera casos similares a éste que se le presenten, lo que equivaldría a decir que, si de él dependiera, cambiaría la ley en cuestión (si de él dependiera, en

\footnotetext{
${ }^{36}$ Kennedy, op. cit., págs. 555-7.

${ }^{37}$ Ibíd., págs. 558 y ss.
} 
efecto, el juez estaría haciendo uso de lo que, entre nosotros, ha estudiado Marina Gascón como «la técnica del autoprecedente» ${ }^{38}$, en cuanto diferente del «precedente vertical»o de respeto a la jurisprudencia de los tribunales superiores y del «precedente horizontal» o de respeto a la jurisprudencia de los tribunales homólogos, pero basado como ellos en el principio de universalidad de la ley y su aplicación, sólo que mirando, por así decirlo, hacia el futuro más bien que hacia el pasado: se trataría del compromiso que el juez contrae de ser fiel a sus propias decisiones y hasta -si se quiere decir un tanto altisonantemente- de ser «fiel a sí mismo», algo que nuestro juez aceptaría sin duda de buen grado pero que, por desgracia, no parece estarle otorgado en el nivel jurisdiccional en que se mueve el pobre hombre). En estas condiciones, a lo más que puede aspirar con su decisión actual es a «salvar su conciencia», pero la cuestión crucial sería entonces la de saber quién le autoriza a ponerla por encima de la ley.

Cuarta, decidir contra el interdicto sobre la base de un argumento jurídico carente de plausibilidad. Pudiera ser, se dice nuestro juez, que un argumento semejante consiga persuadir a otros aunque a él le parezca una chapuza (y hasta pudiera ser que, si tuviera éxito, él mismo acabara persuadiéndose de que el argumento es mejor de lo que es), pero la cuestión crucial es cómo un juez cometería con buena conciencia la deshonestidad de esgrimir un argumento que decididamente tiene por insostenible.

Quinta y última salida, que en realidad no es sino una variante aún más extremosa de la anterior, a saber, decidir contra el interdicto sobre la base de datos de hecho que al juez le consta que son falsos, como que las sentadas de los huelguistas se produjeron en horas no laborables, que los autobuses no salieron porque la compañía había declarado previamente un cierre patronal o cualquier otro algo más verosímil, pero donde la verosimilitud sólo conseguiría tornar más fraudulenta la conducta del juez (en cuanto a la cuestión crucial en este punto, mejor ni mencionarla).

El soliloquio de nuestro juez concluye de manera un tanto abrupta, además de inconcluyentemente. Como corresponde a un caso de conciencia, la clave de su solución no nos es accesible y Kennedy prefiere interrumpir aquí el análisis: lo que sí da a entender es que, cualquiera que sea la decisión que tome el juez, será una decisión existencial. Esto es, una decisión que le habrá de comprometer como persona, como sujeto moral, y no tan sólo como juez.

En un breve postscripto polémico a su ensayo, el autor retorna por un momento la palabra para descartar, entre otras, dos posibles

${ }^{38}$ Cfr., M. Gascón, La técnica del precedente y la argumentación racional, Madrid, 1993. 
objeciones a su planteamiento. La primera procede de la manera más usual de entender lo que antes llamábamos «el pacto (de todo juez) con el diablo», a saber, la consistente en afirmar que el «imperio de la ley» (la rule of law) impone que -en caso de conflicto entre la ley y la conciencia- lo que tiene que hacer el juez, en cualquier caso, es seguir la ley. Pero eso sería sin más optar por la primera de las cinco salidas que hemos enumerado, y el hecho de que nuestro juez tomase en cuenta por lo menos cuatro posibilidades más demuestra, advierte Kennedy, que las cosas no son tan simples a la luz de una exploración fenomenológica de la conciencia del juez ${ }^{39}$. La segunda objeción procedería de un profesor de Filosofía del Derecho que sofisticadamente argumentara, dirigiéndose al juez, en estos o parecidos términos: «La verdad es que no entiendo por qué le resulta tan difícil «salir del paso». Desde Wittgenstein sabemos que ninguna regla puede determinar por sí sola el alcance de su aplicación. De donde se sigue más o menos directamente (bueno, si Vd. quiere podríamos dar un rodeo a través de la semiótica, el estructuralismo y la teoría de la deconstrucción) que el simple enunciado de una ley no nos dice absolutamente nada por sí mismo y hay todo un mundo de interpretaciones (preconcepciones, presunciones y presuposiciones) antes de poder aclarar cuál sea el «significado» de esa «ley» y cómo se aplica ésta a los «hechos».Y, por supuesto, tampoco está muy claro qué sea un «hecho». Etcétera, etcétera, etcétera».¿Mas qué podría hacer nuestro buen juez ante una andanada como ésa, como no sea sumirse en la perplejidad, un estado de ánimo este último, por cuanto sé, nada recomendable?

A título de conclusión, lo único que se me ocurriría decir a mí es que la conciencia, la conciencia moral, del juez no es algo que éste pueda colgar en el perchero, como hace con el abrigo, al vestirse la toga y pasar a la sala donde aplica la ley. El imperio de la ley es, desde luego, una de las más trascendentales conquistas que nos ha legado la modernidad y a la que en modo alguno habría que renunciar en estos tiempos que, además de «postmetafísicos» según vimos, llamamos «postmodernos». Pero, si algo nos ha enseñado este siglo bastante atroz que estamos acabando, es a apear de las mayúsculas a esas grandes palabras heredadas: la Razón, la Libertad, la Igualdad... y también la Ley, claro, o la Justicia mismas $^{40}$. Nuestro siglo nos ha

${ }^{39}$ Además de descartar una tercera «objeción» (cfr. el Afterword de Kennedy, op. cit., pág. 569), me he tomado la libertad de modificar ligeramente la formulación de las otras dos para mejor acomodarlas al curso de nuestra argumentación.

${ }^{40}$ Puesto que, como se recuerda a continuación, este trabajo comenzaba con una invocación a Kant, séame permitido concluir mi plaidoyer en pro de las minúsculas remitiendo a mi artículo «Kant y el sueño de la razón», en Carlos Thiebaut (ed.), La herencia ética de la Ilustración, Barcelona, 1991, págs. 9-36. 
enseñado, como digo, a «escribirlas con minúsculas», esto es, a escala humana, la escala en la que pueden entrar en conflicto con otros atributos humanos, como ocurre con el conflicto entre las leyes y nuestra conciencia moral. Y puesto que esta última es un atributo, no del Hombre en abstracto y a su vez con mayúscula, sino de los individuos concretos, cada cual habrá de apañárselas con ella como pueda, dado que no hay tampoco prontuarios para resolver los problemas de conciencia.

Al comienzo de este trabajo tuve ocasión de puntualizar que lo opuesto a la asunción de la conciencia moral era la mala fe, esto es, la mala voluntad. A la inversa, Kant decía que lo único verdaderamente bueno en este mundo era una buena voluntad, esto es, la voluntad de prestar oídos a nuestra conciencia, la voluntad, diríamos, de moralidad (y conste que con esto de la «buena voluntad» no estoy tratando de concluir con un motivo navideño, ahora que se aproximan esas fiestas). Desde luego, la buena voluntad no basta por sí sola para garantizamos el acierto moral, que depende también de nuestros actos y sus consecuencias y no tan sólo de nuestras intenciones, pero sin ella ni tan siquiera existiría esa perpetua fuente de desasosiego que es la voz de la conciencia, de la que, sin embargo, no podemos prescindir más que al precio de volvernos inhumanos.

Por mi parte, me gustaría haber podido convencer a mis lectores de que el tema de la conciencia del tribunal era tan importante por lo menos como el del tribunal de la conciencia. Y me gustaría haberles podido convencer porque de lo que sí estoy convencido es de que la inhumanidad del Derecho sería infinitamente más indeseable que la ausencia de todo Derecho. Pero, si no he logrado convencerles, me contentaría, como el juez de nuestro ejemplo, con que aquéllos dijesen «No me ha convencido, pero me ha dado que pensar», puesto que el cometido de la filosofía no es, en definitiva, otro que ése, el de dar que pensar. 
$\triangle$ 